LIMA, Oscar Palma; CARRIERI, Alexandre de Pádua. A contabilidade de óbitos e a organização social da morte no Brasil. História, Ciências, Saúde Manguinhos, Rio de Janeiro, v.27, n.2, abr.-jun. 2020, p.355-373

\section{A contabilidade de óbitos e a organização social da morte no Brasil}

\section{The accounting of deaths and the social organization of death in Brazil}

\section{Oscar Palma Lima ${ }^{i}$}

Doutor em Administração, Faculdade de Ciências Econômicas/ Universidade Federal de Minas Gerais.

Belo Horizonte - MG - Brasil

orcid.org/0000-0002-1441-5747

lima.oscar@gmail.com

\section{Alexandre de Pádua Carrieriii}

ii Professor, Departamento de Ciências Administrativas/ Universidade Federal de Minas Gerais. Belo Horizonte - MG - Brasil

orcid.org/0000-0001-8552-8717 alexandre@face.ufmg.br

Recebido em 7 maio 2018

Aprovado em 13 set. 2018

\section{Resumo}

O artigo visa compreender a formação da contabilidade dos óbitos no Brasil e sua influência no modo como percebemos a morte. Para tanto, analisamos a racionalidade dos sistemas de registro, considerando o seu papel de controle populacional. Em seguida, investigamos como os sucessivos governos criaram e desenvolveram esses mecanismos de monitoramento, considerando o processo modernizador pelo qual o país passa desde finais do século XIX. Por fim, delineamos a disposição das categorias da declaração de óbito e como, por meio desse documento, funciona uma tecnologia inquisitiva que distribui direitos e deveres entre atores e estabelece os elementos preliminares de uma organização social da morte, tendo como campo a cidade de Belo Horizonte.

Palavras-chave: morte; mortalidade; registro; biopolítica.

Abstract

The article aims to understand the development of the way deaths are accounted for in Brazil and its influence on how we perceive death. The rationality of registration systems is analyzed, considering their role in population control. The way successive governments have created and developed these monitoring mechanisms is then investigated, considering the modernizing process through which the country has passed since the end of the nineteenth century. Finally, the arrangement of the categories on the death certificate is described, along with how, through this document, an inquisitive technology that distributes rights and duties between actors and establishes the preliminary elements for a given social organization of death works, focusing on the city of Belo Horizonte.

Keywords: death; mortality; registration; biopolitics. 
$\mathrm{U}$ ma das explicações para a existência dos rituais funerários diz respeito à necessidade do homem de exercer controle sobre a própria morte. Para nós, a morte é uma incógnita: não sabemos se há uma vida após a morte nem temos uma previsão certa de onde, quando ou de que forma ela vai ocorrer. $\mathrm{O}$ fato de a vida poder ser apagada a qualquer momento fez os homens procurarem diferentes modos de exercer algum domínio sobre a natureza aleatória da morte. Seriam exemplos os ritos de passagem, o culto aos mortos, construção arquetípica do mundo divino, que a antropologia social tem estudado há tanto tempo. No nosso presente, no entanto, o encontro com a morte foi dividido, por um lado, num discurso médico especializado e procedimentos burocráticos relacionados e, por outro lado, num sentido intensamente pessoal de perda (Walter, 2002). Sabendo disso, propomos analisar a primeira parte dessa divisa, considerando o desenvolvimento dos sistemas de mortalidade brasileiros. Como metodologia, optamos por cruzar revisão bibliográfica, análise documental e pesquisa de campo (Goldenberg, 1997).

O artigo se compõe de seis partes, incluindo esta introdução. Na segunda parte, tratamos do como as rotinas burocráticas buscaram o controle e a previsibilidade do evento inesperado da morte, por meio do desenvolvimento de sistemas de registro e do refinamento de categorias médicas. Aqui utilizamos o referencial foucaultiano de biopolítica, mecanismo de segurança e governamentalidade. A seguir, fazemos um breve histórico dos sistemas de controle de mortalidade que existem no país, tendo como base esse referencial. Na quarta parte, analisamos a lógica da declaração de óbito (DO) no que pesa a sua finalidade como um sofisticado instrumento de vigilância. Na quinta parte, exploramos o cotidiano de registro de óbito em meio às rotinas burocráticas que ele envolve. No final, concluímos que o sistema de vigilância de óbitos irá distribuir direitos e deveres a instituições públicas e privadas e a indivíduos, estabelecendo os parâmetros basilares para a organização social da morte em cidades como Belo Horizonte.

\section{0 controle da morte: dos rituais aos números e às categorias}

Em seu clássico texto, Blauner (1966) argumenta que a burocratização se torna o meio de controlar a morte em sociedades secularizadas (Weber, 1979). O autor acredita que o declínio da autoridade religiosa e as mudanças nas funções da família subjazem também à transferência dos assuntos da morte para os representantes da racionalidade técnica, em instituições especializadas, autônomas de laços de parentesco e que conseguem ordenar a imprevisibilidade de eventos em procedimento-padrão. Se antes era mais comum ver a família cuidar do doente terminal e preparar o cadáver para o funeral, hoje nos acostumamos a associar essas atividades a hospitais e funeral homes, cada qual com o seu conjunto de rotinas específicas (Sudnow, 1967; Glaser, Strauss, 1965, 1968).

Isso quer dizer que, contra o potencial disruptivo e desagregador da morte, cujos efeitos podem "se espalhar para um território social maior e afetar um grande número de pessoas" (Blauner, 1966, p.23), ${ }^{1}$ estabelecemos um número cada vez maior de instituições especializadas - os hospitais, as estatísticas de mortalidade, as instituições que tratam do cadáver etc. Essa especialização seria a nossa resposta ao perigo da mortalidade como ameaça à continuidade do coletivo, pois uma maior coesão social se contrapõe ao potencial 
desagregador que representa. Consequentemente, a imagem da morte como entidade que arrasta indivíduos é substituída pela tabela de expectativa de vida, que permite aos atuários calcular as aposentadorias e aos planejadores de saúde comparar a mortalidade com o ambiente, a nutrição, a renda etc. (Walter, 2002). Assim, para entendermos o que socialmente representa a morte, é preciso lidar com a "questão de como as sociedades modernas se mantêm unidas" (Walter, 1999, p.22).

Howarth (2016) também concorda com a substituição gradual do "pecado" e do "destino" como causas explicativas da morte pela probabilidade estatística, uma mudança de mentalidade que possibilitou o advento de censos de mortalidade baseados no registro de óbitos. Criados para que os Estados gerenciassem os riscos da rápida urbanização (máquinas, doenças profissionais e acidentes), esses "sistemas de registro" têm produzido uma enorme quantidade de números sobre a natureza e a frequência dos óbitos para mapear a sua ocorrência e encontrar modos de evitá-los. Além disso, a maneira de entender e investigar a morte - isto é, "medicalizá-la", entendê-la como uma doença, um risco ou um perigo a ser evitado ou postergado - trouxe ainda mais inovações, como o desenvolvimento de políticas públicas de saúde e a legislação trabalhista.

Quanto a esses sistemas de registro (demografia etc.), é bem claro que, apesar da preocupação central com a morte, eles não falavam de morte per se. ${ }^{2}$ Em vez disso, falavam de "mortalidade" e taxa de mortalidade. Esse seria um ponto significativo no mundo moderno, pois o interesse não recai mais no destino do corpo individual, muito menos na compreensão da morte pelos sujeitos envolvidos, mas antes no "destino das espécies" (Prior, 1989). E as tentativas de registrar e medir os padrões de mortalidade nas sociedades secularizadas têm muitos elementos em comum com o que Foucault (2008a) chamou de "biopolítica" da população. Aparecendo quando a população se converte num objeto privilegiado das técnicas de governo, a biopolítica seria uma maneira de "racionalizar os problemas postos à prática governamental pelos fenômenos próprios de um conjunto de viventes constituídos em população: saúde, higiene, natalidade, longevidade, raça" (Foucault, 2008a, p.431). Técnica de poder aplicada à espécie humana, a biopolítica caracteriza-se como um poder normalizador que se integra à tecnologia do corpo e tem como alvo a população (Calvet, 2008). Ou seja, ela:

centrou-se no corpo-espécie, no corpo transpassado pela mecânica do ser vivo e como suporte dos processos biológicos: a proliferação, os nascimentos e a mortalidade, o nível de saúde, a duração da vida, a longevidade, com todas as condições que podem fazê-los variar; tais processos são assumidos mediante toda uma série de intervenções e 'controles reguladores: uma biopolítica da população' (Foucault, 2003, p.131; destaques nossos.)

A biopolítica é uma dimensão fundamental da governamentalidade. Aliás, estaríamos vivendo na "era da governamentalidade" (Foucault, 2008b, p.145), um momento que se inicia no final do século XVIII, desde quando a tecnologia de governo não parou de ser acossada pela questão do liberalismo, entendida como a questão do "governar demais" (Foucault, 2008a, p.436). Portanto, é inviável compreender o Estado moderno sem referirse às "táticas gerais de governamentalidade", sem referir-se às "táticas de governo que, a 
cada instante, permitem definir o que deve ser do âmbito do Estado e o que não deve, o que é público e o que é privado, o que é estatal e o que é não estatal" (Foucault, 2008b, p.145) - para não cair nos excessos de governamentalidade.

De modo simples, para fins deste artigo, entendemos governamentalidade como "o conjunto constituído pelas instituições, procedimentos, análises e reflexões, os cálculos e as táticas" que permitem exercer uma relação de poder em que (1) o alvo seria a população; (2) a economia política seria a principal forma de conhecimento; e (3) os dispositivos de segurança seriam o instrumento técnico essencial (Foucault, 2008b, p.143). A governamentalidade, nesse contexto, consiste em uma abordagem relacional de ocorrências que vinculam "homens" e "coisas" e que podem incluir "os acidentes ou as desgraças, como a fome, as epidemias, a morte" (Foucault, 2008b, p.129; ver Lemke, 2016). ${ }^{3}$ Também é importante destacar que o surgimento da governamentalidade coincide com a "descoberta da população" e o uso sistemático de números que tornam fenômenos populacionais opacos em um objeto inteligível:

De fato, essa estatística que havia funcionado até então no interior dos marcos administrativos e, portanto, do funcionamento da soberania, essa mesma estatística descobre e mostra pouco a pouco que a população tem suas 'regularidades próprias': seu número de mortos, seu número de doentes, suas regularidades de acidentes (Foucault, 2008b, p.138; destaques nossos).

É nesse momento de descoberta que se lança mão da medição estatística com as primeiras demografias. Assim, pode-se argumentar que o surgimento da população carecia, como também dependia, do surgimento de "mecanismos de segurança" que possibilitaram os cálculos acerca das variáveis de uma população. ${ }^{4}$ Os mecanismos de segurança são dispositivos da governamentalidade que, diferente de um monólito, devem ser compreendidos como um "conjunto decididamente heterogêneo", ainda que estável, de "discursos, instituições, organizações arquitetônicas, decisões regulamentares, leis, medidas administrativas, enunciados científicos, proposições filosóficas, morais, filantrópicas" (Foucault, 2000, p.244).

Ian Hacking (1991, p.185-189) também concorda que o uso dos números como forma de conhecimento sistemático e racionalizado sobre a população seria um pré-requisito fundamental para o surgimento do Estado moderno e o exercício da governamentalidade que o constitui. Ele identificou três eventos históricos interligados na passagem do século XVIII para o XIX que fazem do uso de números um fenômeno da política moderna. Em primeiro lugar, a "erosão do determinismo" pela epistemologia positivista que acompanha o Iluminismo, o que levou a uma atenção crescente ao papel do acaso (indeterminism) para explicar a ocorrência dos eventos sociais. O segundo desenvolvimento, como resposta a essa insegurança recém-descoberta, estaria nas tentativas de "domar o acaso" (taming of chance) por meio do conhecimento das "probabilidades"; considerando a nossa ignorância sobre as verdadeiras causas dos fatos reais da natureza. Por último, uma "avalancha de números"; um aumento exponencial de publicações de figuras numéricas entre 1820 e 1840 na Europa Ocidental, concomitante à expansão e à centralização das burocracias estatísticas. Vistos em conjunto, esses seriam os sinais do "nascimento da estatística moderna". 
Analisando a emergência das estatísticas populacionais da Palestina como tecnologia biopolítica, Jan Busse (2015) sugere haver três processos inter-relacionados no uso governamental dos números, processos que extrapolam a realidade daquele país e que seriam a "problematização", a "normalização" e a "objetivação". Primeiro, os mecanismos de segurança permitem identificar os riscos que a população corre, tornando-os "problemas". A problematização é ela própria política, porque se baliza nas táticas gerais de governamentalidade do Estado (Foucault, 2008b). Ainda segundo o autor, um acontecimento precisa ser antes identificado como um "problema" para depois se tornar um objeto de inquérito estatístico. Essa seria uma característica essencial de um estado "governamental" moderno: os números que ele produz entrelaçam quem governa às pessoas, aos processos e aos problemas que se quer governar; uma vez que esses mesmos números "são 'integrais às problematizações' que moldam o que deve ser governado 'aos programas' que pretendem dar resultado ao governo e à 'avaliação' implacável do desempenho do governo" (Rose, 1999, p.199; destaques nossos).

Em segundo lugar, os aparelhos de segurança não estabelecem um comportamentomodelo ao qual a população deva se conformar, tal como opera o poder disciplinar sobre os indivíduos (Foucault, 2008b). Em vez disso, o procedimento de "normalização" dos mecanismos de segurança identifica primeiro as diferentes curvas de normalidade para depois "fazer uma interação entre essas diferentes distribuições de normalidade [para] funcionarem umas em relação às outras e fazer de sorte que as mais desfavoráveis sejam trazidas às que são mais favoráveis" (Foucault, 2008b, p.83). Por exemplo, no século XVIII, era "normal" uma morte para cada oito casos de varíola, e era necessária uma intervenção se o número de mortes aumentasse. Média da população e projeções sobre seus desenvolvimentos futuros são decisivas, sendo impossível gerir uma série aberta de acasos sem um inventário de elementos e uma estimativa das probabilidades de sua ocorrência (Foucault, 2008b, p.26-27). Nesse sentido, os dados numéricos sistemáticos acerca da população viabilizam os mecanismos de segurança.

Finalmente, os números contribuem para a "objetivação" da população, que se torna "uma espécie de objeto técnico-político de uma gestão e de um governo" (Foucault, 2008b, p.92). Essa objetivação aconteceria de duas maneiras, segundo Jan Busse (2015). Por um lado, os números geram um senso de objetividade que aumenta a credibilidade de quem governa. Indispensáveis à política que se faz hoje, escreve Rose (1999, p.198), os números também despolitizariam áreas inteiras do julgamento político, por "fingirem agir como mecanismos técnicos automáticos para fazer julgamentos, priorizar problemas e alocar recursos escassos". Por outro lado, em um nível instrumental, os números transformam pessoas em "objetos", facilitando o exercício de poder exercido sobre elas. "Aqueles que não se conformam são estigmatizados", enquanto os demais "têm 'internalizado os valores' de uma burocracia cada vez mais onipresente"; de uma burocracia cujo "poder é inseparável da sua objetividade"; e de uma burocracia "pela qual a linguagem opressiva da normalidade e da anormalidade é criada", escreve Porter (1995, p.77-78; destaques nossos). Tal conjuntura permite que a credibilidade dos números seja "frequentemente" aceita sem questionamento, ainda que esses números sejam produzidos no contexto das relações políticas. 


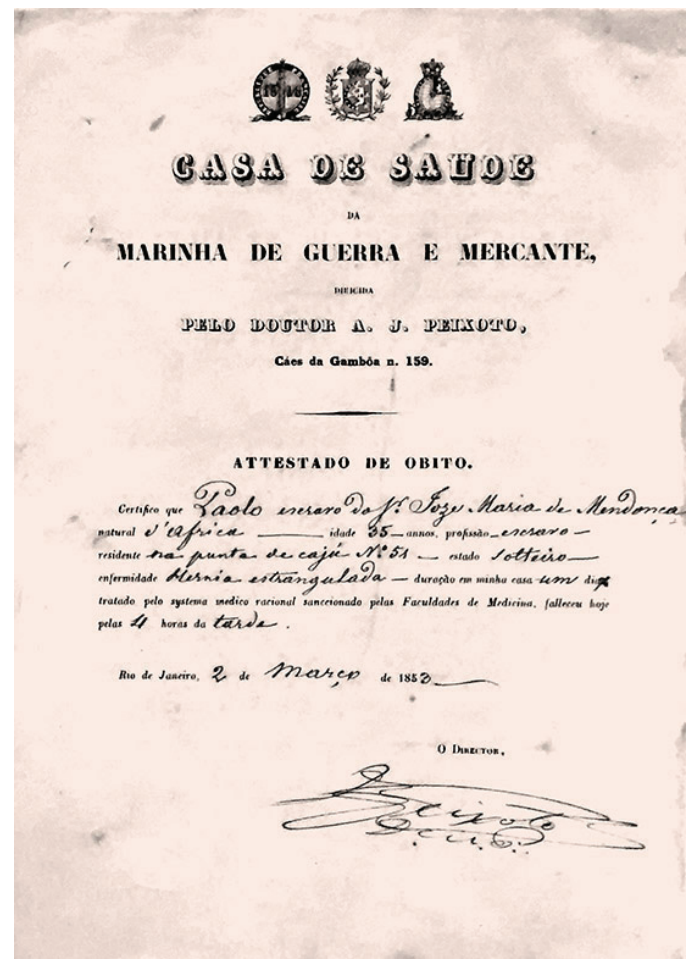

Figura 1: Atestado de óbito do século XIX (Coleção Brasiliana Itaú)

Para Prior (1989), a nossa compreensão da morte foi subordinada aos mecanismos de controle da população e de qualquer coisa que gerasse ou consumisse a saúde e sua vitalidade. Consequentemente, segue o autor, a "mortalidade" foi meticulosamente desmembrada em "categorias" cada vez mais precisas (sexo, idade, causa de óbito etc.). Para medi-la, instrumentos cada vez mais complexos se fizeram necessários, nomeadamente, os diferentes tipos de taxa de mortalidade (infantil, por ocupação, de adultos, de homens e mulheres etc.) e seus componentes ("infantil": neoprecoce, neotardio, pós-neo etc.). Além disso, e em conjunto com esse interesse no destino das populações, "surgiu toda uma série de regulamentos, atividades, organizações e ocupações para coletar, confrontar e analisar os dados associados", tais como o registro civil (nascimentos, óbitos e casamentos); os certificados oficiais e sua devolução; os mecanismos de contabilização; a admissão de registradores, estatísticos e epidemiologistas; além de regras para o desfazimento de cadáveres (Prior, 1989). O autor sugere que são esses instrumentos que estruturam a organização social da morte, muito mais do que as atitudes ou sentimentos perante a morte. Assim, seguindo o seu conselho, iniciaremos as nossas investigações a partir deles.

\section{Os mecanismos de controle da mortalidade no Brasil}

No Brasil, os órgãos públicos que lidam com a mortalidade foram sendo modificados, transformados de acordo com as demandas dos sucessivos governos brasileiros e, após o advento da República, tornam-se parte de um "Estado laico". Essa laicidade deveria ser 
entendida como algo que é mais do que a neutralidade religiosa nos atos de governo; como algo que seria "a condição de possibilidade para a governamentalidade de um Estado" (Diniz, 2013, p.1704). Nesse processo, destaca-se o papel do médico brasileiro, um "herói civilizador" que se sobressaiu em meio a uma elite pouco cultivada do século XIX. Figuras ativas no cenário político, esses profissionais acreditavam "no poder transformador da razão, e na medicina como maior aliado", pois "só o saber especializado do médico levaria o Brasil à altura da civilizada Europa" (Reis, 2012, p.248). Todavia, ainda que houvesse esforços prévios para modernizar o controle da mortalidade no país, como atestam as mudanças no registro civil (Silva, 2000, v.2, p.657-659), a grande mudança ocorre nos anos 1970, quando surgem os dois sistemas de controle de óbito que temos hoje - o sistema do Instituto Brasileiro de Geografia e Estatística (IBGE), em 1973, e o Sistema de Informações sobre Mortalidade (SIM), em 1975. E é a partir da constituição deles que podemos começar a pensar como se organiza a morte no Brasil.

Para Silveira e Laurenti (1973), por "registro" entende-se todo o processo de obtenção de dados por meio de anotação de cada fato ou acontecimento: "como", "quando" e "onde" ele se produziu. No direito, seguem os autores, a função principal do registro é a "publicidade" - tornar conhecida certa situação jurídica que afete os interesses de terceiros. A função do registro seria, consequentemente, garantir e defender um direito. Dos tipos de registro há um chamado de "registro vital", que é o assentamento do estado civil de cada pessoa, que começa com o nascimento e termina com a morte, passando por todos os acontecimentos neste período - casamento, adoção, desquite, tutela etc. Existe aí uma série de fatos e atos jurídicos que resultam em modificações importantes na vida de uma pessoa, conhecidos como "fatos vitais". No nível populacional, o registro desses "fatos vitais" cabe às "estatísticas vitais" que caracterizam uma população.

O "registro de óbito" confirma o status jurídico do falecido (Silveira, Laurenti, 1973). Com a morte, rompem-se todos os laços do indivíduo com a sociedade e desaparecem os "direitos pessoais" inerentes a ele, mas não os "direitos materiais" de seu patrimônio - que passam aos seus herdeiros ou sucessores -, desde que haja o devido registro (Miranda, 1983). No Brasil, durante o Império, não havia registro civil de nascimento e de óbito de católicos, pois eles eram supridos pela certidão de batismo e pelo livro obituário da Igreja (Silva, 2000). No contexto religioso dessa época, os lançamentos paroquiais eram revestidos de todo o valor comprobatório (Silveira, Laurenti, 1973). Apesar das relações existentes entre o Estado e a Igreja, não faltaram tentativas para secularizar o registro civil. O primeiro ato governamental sobre registros de óbito é de 1814, e, em 1870, foi criada uma Diretoria-Geral de Estatística, com competência para gerir os dados de nascimentos, casamentos e óbitos. Mas foi somente com o decreto n.9.886, de 1888, que se estabeleceu a obrigatoriedade do registro civil de nascimentos, casamentos e óbitos; o que fez cessar os efeitos jurídicos dos registros eclesiásticos. Em 1912, elaborou-se um projeto de lei que propunha alterar o decreto n.9.886. Esse projeto de lei trouxe duas importantes novidades: legitimar que o farmacêutico atestasse o óbito na falta de médico e apresentar, pela primeira vez, um modelo padrão de atestado de óbito (Silva, v.2, 2000). Historicamente, o decreto n.9.886 inaugura no país a obrigatoriedade de apresentar o atestado de óbito com a causa (médica) da morte para poder fazer o registro (civil) de óbito (Vasconcelos, 1998). 
Conforme escreve Vasconcelos (1998), apesar da obrigatoriedade do atestado de óbito, as estatísticas de óbito permaneceram deficientes durante muitos anos, excetuando o estado de São Paulo e algumas capitais do país. O sub-registro de nascimentos e óbitos ${ }^{5}$ e a desorganização do sistema de estatísticas vitais apareciam como os principais problemas. Com o intuito de melhorar as "estatísticas vitais", em 1973, o governo federal atribuiu ao IBGE a responsabilidade por produzir as estatísticas vitais brasileiras aos moldes da Organização das Nações Unidas. O órgão padroniza a sua coleta em nível nacional junto aos Cartórios de Registro Civil e consegue melhorar a coleta dos eventos vitais (Jorge, Laurenti, Gotlieb, 2009). Também em 1973, houve a aprovação da Lei dos Registros Públicos Brasileira, que vincula o sepultamento ao registro de óbitos (Brasil, 31 dez. 1973). Desde então, a declaração médica de óbito atende a essa lei, enquanto o governo tenta também diminuir os cemitérios clandestinos no país, lugares associados à pobreza e prevalentes na área rural, e que realizam sepultamentos sem exigir certidão (Szwarcwald et al., 2002).

Apesar da modernização, o sistema de controle apresentava algumas falhas, sobretudo porque os "mapas de óbitos" produzidos pelo IBGE, ainda que tenham um grande nível de detalhamento sobre o falecido, não informam a "causa da morte"; registrando apenas a sua "natureza" (natural ou violenta). A ausência da informação sobre a causa da morte no sistema de informações do IBGE, além da pressão política de organizações internacionais para que isso fosse realizado no país, fez o Ministério da Saúde (MS) implantar mais um sistema de controle da morbimortalidade em 1975 (Jorge, Laurenti, Gotlieb, 2009). Nesse ano, surgia o SIM, que tinha o objetivo principal de produzir estatísticas de mortalidade "por causas" em todo o território nacional. O novo sistema de controle possibilitou ao MS introduzir a DO, um modelo nacional de certificado que conformava os diagnósticos médicos com a nomenclatura do Código Internacional de Doenças (CID), seguindo a recomendação da Organização Mundial de Saúde.

Ainda assim, a análise do aparecimento do SIM fica incompleta quando se desconsidera a conjuntura nacional em que ele aparece (Viana, Machado, 2009). O SIM é lançado no ano seguinte ao segundo Plano Nacional de Desenvolvimento (II PND), que veio a público em 1974 (Brasil, 1974). Entre outros motivos, o II PND é importante por ter sido o primeiro programa do regime militar a reconhecer que o desenvolvimento social deveria acompanhar o desenvolvimento econômico (Escorel, 2012). Uma das prioridades do II PND no campo social era o setor de saúde, cujo diagnóstico à época era de que carecia de capacidade gerencial e estrutura técnica, o que estaria levando a uma "crise sanitária"6 (Escorel, 2012).

Para Hésio Cordeiro (1980, p.163; destaques no original), “[a] 'conjuntura sanitária' assinala o fim do milagre econômico e indica um estado de 'insolvência sanitária', com aumento dos gastos com hospitalizações ao mesmo tempo que se reduzem gastos em Saúde Pública". Diante desse cenário, os burocratas do governo se perguntavam: "por que motivos a Revolução, que superou tantos antagonismos para tirar o País do subdesenvolvimento, não consegue pôr ordem em nosso caótico sistema de assistência médica e sanitária?". A saída proposta por eles incluía acessar o "estado sanitário" da população brasileira, por meio dos "elementos que compõem a 'estatística vital ou bioestatística"'; elementos que "não dão a medida da saúde, mas sim os 'efeitos' ou consequências das doenças que matam" 
(Bastos, 1977, p.34-35; destaques nossos). A resposta daquele governo à crise sanitária que se seguiu ao período do "milagre" ocorreu mediante "políticas racionalizadoras" que "incorporavam a ideologia do planejamento de saúde como parte de um projeto de reforma de cunho modernizante e autoritário" (Paim, 2008, p.70). A partir de 1975, e por meio do II PND, o MS teve seus recursos aumentados, o que lhe possibilitou desenvolver redes de projetos e pessoas, financiar pesquisas, contratar profissionais, fomentar a articulação com as secretarias estaduais de saúde, elaborar propostas alternativas para os serviços de saúde e os recursos humanos (Escorel, 2012) - o que certamente viabilizou o SIM naquele ano.

Uma vez que os gestores do MS implantam o SIM, aparecem duas novidades (Vasconcelos, 1998). A primeira foi um controle maior das características sociodemográficas do falecido e das circunstâncias do óbito segundo a nosologia internacional, a conhecida Classificação Internacional de Doenças, que se encontra hoje na sua décima revisão, CID-10 (OMS, 1995). A outra novidade é a descentralização do SIM, pois o sistema do IBGE é centralizado. Essa descentralização aumenta em 1991, no contexto da transição democrática e do federalismo que a acompanha, quando as secretarias estaduais e municipais de saúde passam a coletar os dados para o SIM diretamente de hospitais, cemitérios e unidades de saúde (Viana, Machado, 2009; Jorge, Laurenti, Gotlieb, 2009).

Apenas introduzir o novo modelo, no entanto, seria insuficiente para atingir os objetivos governamentais. Em primeiro lugar, foi preciso produzir uma legislação para que o sistema funcionasse (Jorge, Laurenti, Gotlieb, 2009). Uma legislação que, entre outras medidas, obriga o uso da DO para o registro de óbitos em cartórios (Brasil, 31 ago. 2000), que pune os médicos que negam a fornecer a DO e que prevê suspensão de recursos para programas de atenção básica à saúde para a secretaria municipal de saúde que deixar de alimentar os sistemas de informação em saúde - o que inclui o SIM - por dois meses seguidos (Brasil, 4 set. 2012, art. 6). Em segundo lugar, a difusão de farto material didático, produzido pelos funcionários do Centro Brasileiro de Classificação de Doenças (CBCD), para a formação de médicos, estudantes e funcionários públicos (Jorge, Laurenti, Gotlieb, 2009). Além disso, há recursos para que os meios acadêmicos e as secretarias municipais e estaduais de saúde realizem estudos sobre a qualidade da vigilância epidemiológica desse sistema.

Assim, desde os anos 1970, há dois sistemas independentes de controle de óbitos no Brasil - o do IBGE (sistema de estatísticas de registro civil) e do Ministério da Saúde (sistema de informações sobre mortalidade) -, evidenciando uma grande estrutura para coleta, consolidação e publicação das estatísticas nacionais de mortalidade (Vasconcelos, 1998). Os dois mecanismos de segurança populacional têm utilidades diferentes. Atualmente, a tabela de mortalidade do IBGE subsidia o cálculo do "fator previdenciário", feito pelo Ministério da Previdência Social, para fins das aposentadorias sob o Regime Geral da Previdência Social (Brasil, 4 set. 2012). Já o SIM permite monitorar a saúde da população em seu tempo e seu espaço de ocorrência, identificar os pontos de risco e, por conseguinte, gerenciar os programas de saúde - pesquisa, prevenção etc. (Lebrão, 1995).

Em comum, escreve Vasconcelos (1998), os dois sistemas de controle da mortalidade são minuciosos quanto aos procedimentos de registro, às taxas cobradas e às penalidades e multas para os eventos não registrados. Poderíamos pensar, a partir de Foucault, duas 
questões importantes. Em primeiro lugar, um setor público que atua como um "tutor pleno" que legisla, planeja, executa, compra, financia e fiscaliza os serviços de saúde relativos à mortalidade da população. Em segundo lugar, esses sistemas de controle de mortalidade ajudando a "institucionalizar" uma compreensão "medicalizada" da morte, que tem efeitos consideráveis de nossas atitudes para com ela. Por exemplo, a partir do momento da morte, nos bastidores, o corpo se torna objeto de investigação de uma série de profissionais que detêm a sua posse para que ele seja examinado, certificado e vestido. Afinal, conforme indica Parsons (1997), em conjunto com a mudança de atitudes perante a morte e a mudança do corpo para o ambiente médico institucionalizado, aumentou-se a formalização dos aspectos associados à morte e ao processo de eliminação do cadáver - o que implica maior participação de empresas especializadas, no lugar das famílias e das comunidades.

\section{O detalhamento do óbito}

A DO seria o eixo de todas as regras e as práticas que ligam um complexo sistema médico, legal e administrativo (que inclui o SIM). As regras, as nosologias e as categorias de descrição e de explicação podem ser capturadas nos manuais do governo federal que explicam como selecionar e classificar as causas de morte; nas leis que regem o registro e o desfazimento dos mortos; no discurso da medicina ocidental; e nas "práticas" humanas de selecionar, aplicar e adaptar todas essas normas para organizar a realidade social (Brasil, 2007; Prior, 1989). Sobre a DO como ponto central de todo esse sistema, nos escreve Schneidman (1976, p.246): "No mundo ocidental, à morte é dada a sua dimensão administrativa pelo atestado de óbito. São seus formato e conteúdo que determinam e refletem as categorias nos termos em que a morte é conceituada e as estatísticas de óbitos são relatadas".

O documento básico do SIM é a DO (Brasil, 11 fev. 2009), por meio do qual o médico atesta o falecimento de alguém e encerra a existência da "pessoa natural". Em tese, o preenchimento de oito das nove partes da DO é de "responsabilidade do médico", 7 de modo que é ele que certifica a morte e declara a sua causa, ou causas (Brasil, 11 jan. 1932). Em campo, vimos que a associação entre a morte e a DO é tão próxima que um médico que assiste um paciente grave pode confirmar que a morte se aproxima, ao afirmar que estará disponível a qualquer momento para fazer a declaração. O documento é bastante detalhado, afinal, ele é uma prova jurídica de que o indivíduo não mais existe e serve para proceder com o sepultamento do corpo. Foucault, embora em outro contexto, também notou a significância política de investigações como essa, assim como a importância do "caso" e "história do caso" em geral. Ele afirma:

Durante muito tempo a individualidade qualquer - a de baixo e de todo mundo - permaneceu abaixo do limite de descrição. Ser olhado, observado, contado detalhadamente, seguido dia por dia por uma escrita ininterrupta era um privilégio. ... Os procedimentos disciplinares reviram essa relação, abaixando o limite da individualidade descritível e fazem dessa descrição um meio de controle e um método 
de dominação. Não mais monumento para uma memória futura, mas documento para uma utilização eventual. ... Esta transcrição por escrito das existências reais não é mais um processo de heroificação; funciona como processo de objetivação e de sujeição. A vida cuidadosamente estudada dos doentes mentais ou dos delinquentes se origina ... de uma certa função política da escrita (Foucault, 2012, p.215-216).

Mas o detalhamento inquisitivo que encontramos hoje numa DO nem sempre existiu. Conforme Camargo (2007), na cidade de São Paulo, até por volta de 1860, a maioria dos conhecidos "atestados" ou "bilhetes de sepultamento" não era redigida por médicos, e sim por padres, que os faziam em tiras de papel e, em muitos casos, as cortavam à mão. Esta era uma das várias funções dos religiosos, que incluía, por exemplo, dar a extrema-unção. Naquela época, era um costume muito arraigado no povo chamar um padre, e não um médico, para acompanhar os últimos momentos do doente. Para atestar a morte, em geral, os clérigos se valiam das informações passadas por familiares e pessoas próximas ao falecido - semelhante ao que alguns médicos fazem hoje, ainda que contra o status científico que a prática médica adquiriu (Silva, 2000). Em muitos casos, não havia indicação da causa mortis nos "bilhetes de sepultamento", considerando que para a Igreja, e para a maioria das pessoas da época, o fato de que "foi Deus quem quis" chamar a si determinado indivíduo já seria uma explicação suficiente.

A partir de 1858, ainda segundo o autor, a legislação sobre enterramentos passou a exigir atestado médico que certificasse o óbito e que incluísse "a moléstia de que faleceu" e "a sua duração". A obrigatoriedade de um médico verificar o óbito antes do sepultamento do corpo não se vinculava apenas a questões sanitárias, ou de uma ciência que lentamente ganhava terreno em relação a práticas "não esclarecidas" (pois era comum chamar curandeiros se havia suspeita de feitiço), mas também a uma "dimensão policial da morte", porque a ausência de uma "autoridade idônea" que verificasse o cadáver possibilitaria que os óbitos por causa criminosa (sobretudo, os crimes domésticos) passassem despercebidos pelas autoridades (Camargo, 2007). É bem verdade que, atualmente, as dimensões policial e sanitária continuam sendo duas das grandes finalidades do atestado de óbito, aproximando a ciência da morte à ciência do crime (Silveira, Laurenti, 1973, p.43).

\section{O controle médico e familiar}

Há um grande rigor no controle logístico para a distribuição e o recolhimento desses formulários. A priori, isso resolveria o problema do comércio de DOs pelas agências funerárias, que possivelmente iriam comercializá-las, ainda que assinadas por médicos (Jorge, Laurenti, Gotlieb, 2009). Embora essa saída não reprima todos os casos ilícitos, pelo menos, segundo o que aparece esporadicamente nos jornais, o percurso de uma DO serve de preâmbulo da organização social da morte em cidades como Belo Horizonte. Esquematicamente, cada uma das três vias da DO percorre vários passos, conforme o fluxograma ilustrado na Figura 2. 


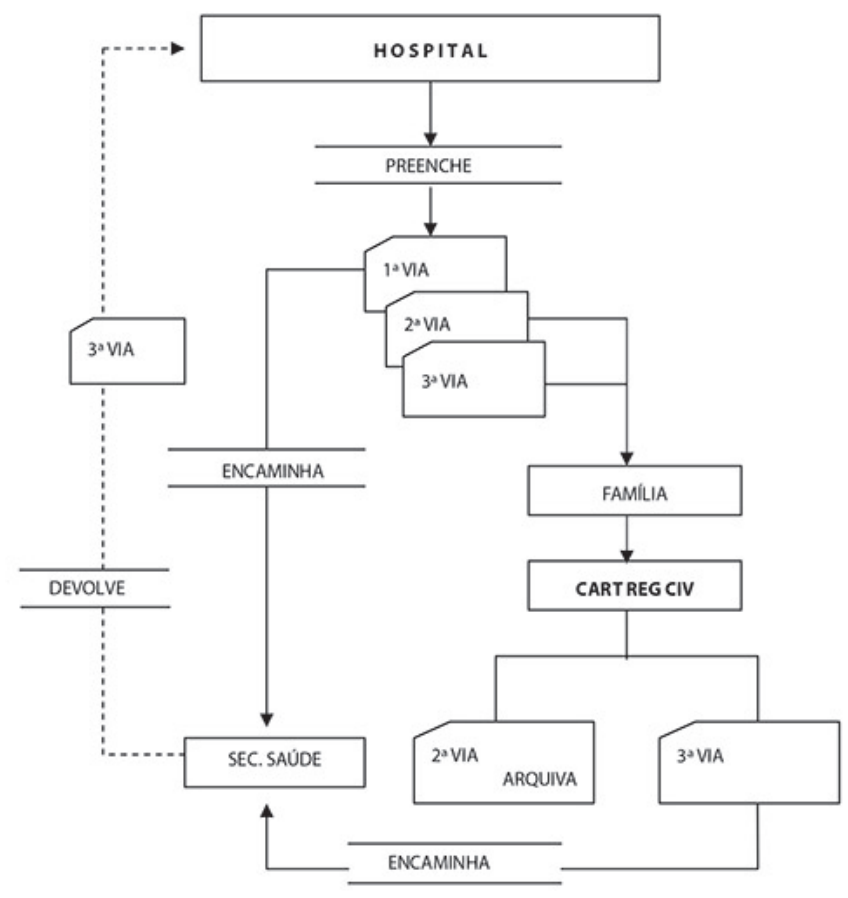

Figura 2: Fluxograma da informação de óbitos hospitalares (Adaptado de Brasil, 2001, p.32-33)

O fluxograma na Figura 2 representa uma rede formal em que transita a DO. O domínio do pessoal e dos ambientes médicos, dos agentes legais, dos encarregados de burocracias estatais e, claro, dos parentes próximos é evidenciado no fluxograma. Assim como alguns agentes e cenários estão incluídos, outros são excluídos. Nesse cenário dominado pela burocracia e pela ciência médica, vemos que a responsabilidade pelo documento é de competência da família e de pelo menos três instituições: o estabelecimento de saúde, a secretaria municipal de saúde e o cartório de registro civil. O fluxograma não menciona, por exemplo, funerárias, seguradoras, líderes comunitários ou amigos. Isso não quer dizer que alguns desses atores não participem dos rituais funerários, mas é incontestável que eles são supérfluos para essa burocracia que descobre, define e atribui as causas de morte. Eles estão bastante engajados nesse processo, como nos falou um atendente de funerária, entrevistado junto a sua mesa de trabalho dentro de um grande hospital:

Geralmente, o médico ou a enfermeira responsável já orienta que tem que estar com a identidade da pessoa que faleceu para eu poder fazer o registro e iniciar o processo da declaração de óbito... eu faço o registro, eu colho os dados e esses dados são levados à internação ... Na internação, tem um funcionário responsável que faz a declaração de óbito e o médico coloca as causas do óbito e assina ... a família pega a declaração de óbito, que é esse documento, e vai até o cartório para ser feito o atestado de óbito ... o corpo só é sepultado quando registrado em cartório ... pode ter feito velório normalmente, mas só é sepultado se tiver o registro do cartório (E33). ${ }^{8}$

Conforme ficou evidente na fala anterior, no fluxograma e também na lei de registros civis (Brasil, 31 dez. 1973), um dos atores mais ativos no processo de desfazimento do 
corpo é a família do falecido, que, no momento que sucede o óbito, percorre um itinerário muito diferente do que segue o cadáver (Bradbury, 1999). A exemplo de Belo Horizonte, após obter uma DO assinada pelo médico que acompanhou o caso (se a pessoa faleceu num hospital) ou pelo médico que assistiu o falecido (se a morte aconteceu em casa e não há suspeita de crime), ou pelo médico do Instituto Médico Legal (IML) que fez a autópsia (no caso de mortes violentas), a família enlutada é instruída a levar o formulário para o cartório de registro civil da comarca onde sucedeu o óbito. Geralmente, registra-se o óbito no dia de ocorrência. No cartório, tomar-se-ão notas dos detalhes da morte, dos dados da pessoa falecida ${ }^{9}$ e do cemitério ou crematório para onde será encaminhado o corpo, antes de liberar gratuitamente a certidão de óbito e a guia de sepultamento.

Se a lista de documentos estiver completa, o registro dura, em média, 15 minutos. Do cartório se sai com a certidão de óbito - a via original e pelo menos uma cópia que ficará arquivada no cemitério ou crematório - e a guia de sepultamento. Nenhum corpo pode ser eliminado sem esses papéis. Em posse desses dois documentos, e após conferir os documentos pessoais do responsável e cobrar dele as taxas administrativas para abrir e fechar o jazigo, o cemitério emite a autorização para sepultamento. Enquanto seus associados vão ao cartório, as funerárias costumam agendar o velório e o enterro ou a cremação. A funerária só pode operar no cadáver em posse da certidão de óbito e da autorização de sepultamento.

O que pode parecer fácil no organograma, na verdade não é. Comunicar o falecimento no cartório vem acompanhado de diversas dificuldades, as quais a família deve gerir para continuar com os trâmites legais para o desfazimento do cadáver. Tudo se faz sob o impacto de uma perda recente, o que dificulta a concentração nas tarefas mais simples necessárias para realizar o registro (Bradbury, 1999). Em momentos como esse, quando o zelo burocrático parece pedante ou trivial, é comum a irritação dos familiares com os atendentes dos guichês quando eles pedem um documento que faltou, uma informação do falecido que se perdeu ou para esperar mais pelo atestado de óbito. Se, normalmente, as exigências burocráticas incomodam, no momento do luto elas se tornam muito mais irritantes: seja ter de voltar ao hospital para pegar a guia que foi esquecida, confirmar a informação registrada no computador ou consultar um parente ao telefone para lembrar o registro daquela propriedade, o nome de parente ou qualquer outro dado do falecido. $\mathrm{O}$ risco de o familiar passar informação errada aos atendentes é alto, o que exige deles algum autocontrole emocional que eles declaram ter aprendido no cotidiano de seu trabalho. A orientação das funerárias a seus associados faz parte dos serviços que oferecem ou, para aqueles que não têm um plano funerário, uma primeira abordagem de vendas:

A gente tem que passar orientação de cartório, a gente tem que passar orientação de cemitério ... é necessário, porque a gente está ali para isso ... o trabalho é isso ... quando acontece o óbito, em alguns hospitais a gente busca a família também (E52). Tem muitas famílias que chegam chorando muito, aí eu preciso que alguém da família que esteja melhor venha acolher, porque tem muitas informações a serem passadas e a pessoa não está apta a receber informação nenhuma devido ao estado psicológico. A gente dá um acolhimento, conversa com a família, verifica como é que está ... tem família carente que não tem condição nenhuma de atendimento funerário, e a gente faz uma entrevista para ver como estão as condições da família, como que ela tomará as providências funerárias. Aí aqui a gente inicia tudo isso (E33). 
Ademais, ainda que a família nem sempre precise percorrer longas distâncias, como se verifica no meio rural, nos bairros de periferia e na região metropolitana das capitais, uma dificuldade adicional é encontrar o cartório aberto da comarca do local do falecimento quando o óbito ocorre fora do horário comercial (das nove da manhã às cinco da tarde durante a semana). ${ }^{10}$ Esta dificuldade aumenta nos fins de semana e feriados, quando só o cartório que foi escalado entre oito existentes na região metropolitana está aberto em regime de plantão, ainda que funcionando em horário comercial. ${ }^{11}$ Conforme um entrevistado nos disse:

As áreas são divididas por regiões. Então se uma pessoa morreu lá no Venda Nova e ela vier para o IML, quando o médico legista do IML declara o óbito, ela não vai no cartório perto do IML, ela vai no cartório onde faleceu, que é o cartório regional de Venda Nova. Os cartórios de hoje em dia não têm plantão 24 horas. Só funcionam no horário comercial, mesmo em plantão final de semana e feriado ... tem dia que você chega na porta de um cartório tem dez, 15 famílias ali e demora um pouco declarar o óbito. ... Cada cidade tem o seu cartório ... em algumas cidades como Santa Luzia, por exemplo, já tem um cartório da região de São Benedito. Cada região que evolui, eles criam um cartório ali para cobrir aquela região enorme (E02).

Outra dificuldade é manusear a papelada de registro, com uma variedade de documentos que precisam ser localizados e organizados, para que a ida ao cartório aconteça somente uma vez. Há ainda o fato irritante de que nos cartórios, como na maioria das instituições que trabalham com o óbito, os funcionários têm pouco ou nenhum preparo para atender pessoas enlutadas. A sensação de quem está recebendo o serviço faz lembrar o testemunho da jovem enfermeira que se viu na condição de moribunda: "Para vocês, a morte faz parte da rotina. Para mim, ela é nova e única” (Ziegler, 1977, p.206). A prova de resistência às práticas rotineiras do pós-óbito não termina aí. Além disso, há ainda de resolver a documentação relativa à contratação do serviço funerário:

É muita informação: documentação, cartório, procedimentos funerários ... porque quando a família faz o serviço, ela tem que assinar muitos formulários ... é a autorização do tratamento, a ficha de autorização do serviço contendo valores, os itens que ela está adquirindo, a autorização do serviço com o acordo de que o serviço funerário não cobre as taxas do cemitério ... assinar a frase de coroa, porque a família escolhe uma frase de coroa ou homenagem de luto ... são várias assinaturas ... porque é muito delicado quando você mexe com corpo de um familiar ... então tem que autorizar o tratamento, desde um barbeamento até a venda de uma urna ... porque qualquer erro pode virar infração, né? Pode ocorrer um problema muito grande porque você está mexendo com corpo do ente querido de alguém (E33).

Como vemos na fala, após a confirmação da morte, o corpo se torna um "objeto" de diferentes práticas instrumentais, cada qual atuando sobre partes e órgãos específicos dele: a autópsia, a tanatopraxia, o registro etc. Assim como os mortos só são vistos como "mortos" até que um médico os declare como tal (Sudnow, 1967; Glaser, Strauss, 1965, 1968), a morte não é reconhecida burocraticamente até que o cartório lavre a certidão de óbito. Esse reconhecimento é o que torna a certidão de óbito (e, indiretamente, a DO) um documento indispensável para reorganizar o status social e familiar após a morte de alguém (Silva, 2000). 
"Indispensável" porque a falta desse documento inviabiliza uma série de benefícios relativos ao morto e aos seus familiares, por causa disso há um corpo de funcionários públicos disponíveis para fazê-lo (Silva, 2000). Por esse motivo, é muito pouco provável que se proceda qualquer ritual mortuário em Belo Horizonte antes de a certificação ocorrer.

Este texto, contudo, não estaria completo sem nos referirmos à grande mudança que acompanha esse aspecto da nossa sociedade em que tudo é regulado, controlado e certificado. Estamos tratando da mudança da percepção moderna que acompanha essa burocracia. Lembremos que os dois tipos diferentes de atestado de óbito (ainda que se assemelhem em aparência) são entregues sem lacre e podem ser lidos em qualquer momento. Como observou Prior (1989), as suas categorias frequentemente se tornam assunto no círculo de parentes e amigos do falecido. De fato, durante a nossa pesquisa, vimos que elas alimentam as conversas sobre os últimos momentos do morto, porque sempre se quer saber de que ele morreu, qual doença estava no seu corpo, há quanto tempo ele estava sofrendo e se a morte dele não teria sido uma "bênção" para todo mundo. Já a resposta preferida à pergunta sobre como e por que uma pessoa morreu, em geral será sobre a doença ou a ineficácia da medicação ou do tratamento - pois hoje se morre muito mais de doença do que velhice, pecado ou infortúnio. Essa transformação de percepção da morte seria a consequência definitiva da atualidade em que vivemos e que pode ser entendida como uma crise da experiência narrativa, cuja substância é existência vivida (Benjamin, 1985). Revisitando esse trajeto que resolvemos percorrer de nossa história, "as estatísticas de mortalidade atuaram como um ponto de articulação para várias mudanças na percepção da natureza dos corpos, da saúde e das populações" (Armstrong, 1987, p.654). E como alhures, isso também parece ter ocorrido por aqui.

\section{Considerações finais}

Neste artigo nos concentramos na construção social da morte e no papel da burocracia atuando como elemento de coesão. Como vimos, essa coesão passa pelo funcionamento de uma "tecnologia panóptica", pois, enquanto as famílias transitam de uma instituição a outra, elas são induzidas a participar de diferentes formas de inquérito e confissão para prover as informações necessárias aos sistemas de controle de mortalidade (Foucault, 2012). Já a construção social (e simbólica) "reduziu as mortes a seus aspectos físicos", porque a importância dos "corpos biológicos" sobre o "corpo social" é uma das características centrais dos discursos (essencialmente médicos) dentro dos quais a morte é analisada, compreendida e relatada (Prior, 1989). Assim sendo, se a linguagem em geral tem as suas próprias regras e convenções e se há instituições em que esse discurso é produzido e divulgado, essa afirmação também vale para a medicina, cujo discurso produz conhecimentos e ocupa instituições e espaços profissionais específicos (Nead, 1988). Isso não quer dizer que esses espaços e instituições sejam exclusivamente de saúde. Como argumentamos neste artigo, se, devido à sua autoridade, o discurso médico produz posições de sujeitos como médicos, enfermeiros e pacientes, não é de estranhar que ele também produza as posições de moribundos, falecidos e familiares; nem que ele estabeleça os limites, as atividades e as percepções relativas de como organizamos a nossa relação com a finitude da vida. 


\section{AGRADECIMENTO}

Agradecemos ao Conselho Nacional de Desenvolvimento Científico e Tecnológico (CNPq) pelo auxílio financeiro.

\section{NOTAS}

${ }^{1}$ Nessa e nas demais citações de textos em inglês, a tradução é livre.

${ }^{2}$ Para Foucault (2012, p.296), aliás, a morte - termo da vida - seria o limite de qualquer relação de poder. A morte estaria "do lado de fora" do domínio do poder, sendo que "o poder só terá domínio de modo geral, global, estatístico. Isso sobre o que o poder tem domínio não é a morte, é a mortalidade".

${ }^{3}$ Conforme observa Lemke (2016), essa ligação nos foi possível pelo fato de Guillaume de La Perrière (14991533) considerar "governo" "a correta disposição das coisas, das quais alguém se encarrega para conduzi-las a um fim adequado" (citado em Foucault, 2008b, p.130). De acordo com Foucault, a noção de La Perrière de "governo das coisas" não se trata de opor coisas aos homens, "mas uma espécie de complexo constituído pelos homens e pelas coisas" (p.128). Ainda assim, nesta perspectiva de ajuntamento "sujeito-objeto", como é o caso da população, um conjunto de corpo material e intenção, a governamentalidade poderia determinar os limites do que seria humano (logo, dotado de uma existência sociopolítica) e do que seria não humano (e, consequentemente, a "pura matéria") (Lemke, 2016; Foucault, 2008b).

${ }^{4}$ Segundo Jacques Revel (1990, p.159-169), com a estatística surge um corpo coletivo e um espaço contínuo e abstrato em que qualquer ponto é, por definição, igual a outro. Se antes da estatística existiam apenas os moradores, com essa instituição surge a população. Por meio dos mapas demográficos torna-se possível conhecer informações detalhadas das doenças que afetam a população, do grupo mais atingido e da extensão do mal causado. As estratégias de combate à mortalidade seriam traçadas com base nesses dados.

${ }^{5}$ Entre as causas do sub-registro incluem-se a pobreza; a existência de regiões de difícil acesso, distantes de cartórios e de serviços de saúde; os sepultamentos "clandestinos" em regiões rurais; o analfabetismo; e a falta de interesse da população, que não vê benefícios no registro civil (Vasconcelos, 1998).

${ }^{6}$ Até meados de 1974, o governo impedia que as notícias diárias sobre epidemia de meningite e o aumento da mortalidade infantil chegassem à imprensa (Gaspari, 2004, p.108-109).

${ }^{7}$ Conforme Niobey et al. (1990), o que acontece com frequência é que alguns médicos se concentram na parte "médica" do documento (Bloco V) e deixam para os funcionários administrativos o preenchimento de campos "menos nobres" da declaração de óbito.

${ }^{8}$ As entrevistas foram gravadas com auxílio de um roteiro semiestruturado, mantendo o anonimato dos participantes. Elas aconteceram entre abril e junho de 2017, em horário comercial. Além das entrevistas gravadas, realizaram-se conversas informais, observação participante e a confecção de um diário de campo. Foram entrevistados 81 atores sociais (E1 a E81) ligados à indústria mortuária.

${ }^{9}$ Há os documentos do falecido que devem ser apresentados: Certidão de Nascimento (se solteiro); Certidão de Casamento (se casado); Certidão de Casamento e Certidão de Óbito do Cônjuge (se viúvo); Certidão de Casamento com averbação (se divorciado ou separado judicialmente); Carteira de Identidade; CPF; Título de Eleitor ou comprovante de votação ou certidão do TRE; Número do benefício e número da Espécie (se aposentado ou pensionista do INSS).

${ }^{10}$ Em Belo Horizonte há seis cartórios onde se faz registro de óbito, localizados nos seguintes bairros: Floresta, Centro (dois cartórios), Lourdes, Nova Suíça e Venda Nova. Também atendem à região metropolitana dois cartórios localizados na cidade de Contagem, nos bairros Centro e Eldorado. Bimestralmente, esses cartórios fazem um rodízio para atendimento nos finais de semana e feriados.

${ }^{11}$ Sobre os detalhes dos plantões para o registro de óbito, conferir os artigos 46 a 53 do Provimento n.260/ CGJ/2013 (Minas Gerais, 30 out. 2013). 


\section{REFERÊNCIAS}

ARMSTRONG, David.

Silence and truth in death and dying. Social

Science and Medicine, v.24, n.8, p.651-657. 1987.

BASTOS, Murillo Villela.

O sistema nacional de saúde em debate. Revista de Administração Pública, v.11, n.3, p.31-56. 1977.

BENJAMIN, Walter.

O narrador. In: Benjamin, Walter. Magia e técnica, arte e política: ensaios sobre literatura e história da cultura - obras escolhidas, v.1. São Paulo: Brasiliense. p.197-221. 1985.

BLAUNER, Robert.

Death and social structure. Psychiatry, v.29, n.4, p.378-394. 1966.

BRADBURY, Mary.

Representations of death: a social psychological perspective. London: Routledge. 1999.

BRASIL.

Ministério da Saúde. Gabinete do Ministro. Portaria n.1.882, de 4 setembro de 2012.

Disponível em: < http://bvsms.saude.gov.br/ bvs/saudelegis/gm/2012/prt1882_04_09_2012. html>. Acesso em: 5 fev. 2020. 4 set. 2012.

BRASIL.

Ministério da Saúde. Secretaria de Vigilância em Saúde. Portaria n.116, de 11 de fevereiro de 2009. Disponível em: < http://bvsms.saude.gov.br/ bvs/saudelegis/svs/2009/prt0116_11_02_2009. html>. Acesso em: 5 fev. 2020. 11 fev. 2009.

BRASIL.

Ministério da Saúde. A declaração de óbito: documento necessário e importante. Brasília: Ministério da Saúde. 2007.

BRASIL.

Ministério da Saúde. Manual de procedimentos do Sistema de Informações sobre Mortalidade. Brasília: Fundação Nacional de Saúde, Ministério da Saúde. 2001.

\section{BRASIL.}

Ministério da Saúde. Fundação Nacional de Saúde. Portaria n.474, de 31 de agosto de 2000. Disponível em: <http://www. funasa.gov.br/documents/20182/47176/ portaria_474_2000.pdf/0b672f51-b2b7-423ca0b6-d03364c201be?version $=1.0>$. Acesso em 5 fev. 2020. 31 ago. 2000.

BRASIL.

II Plano Nacional de Desenvolvimento (1975-79). Brasília: Imprensa Oficial. 1974.

BRASIL.

Lei n.6.015, de 31 de dezembro de 1973.

Dispõe sobre os registros públicos e dá outras providências. Disponível em: < http://www. planalto.gov.br/ccivil_03/LEIS/L6015original. htm>. Acesso em: 4 fev. 2020. 31 dez. 1973.

BRASIL.

Decreto n.20.931, de 11 de janeiro de 1932. Disponível em: <http://www.planalto.gov.br/ ccivil_03/decreto/1930-1949/D20931.htm>. Acesso em: 5 fev. 2020. 11 jan. 1932.

BUSSE, Jan.

The biopolitics of statistics and census in

Palestine. International Political Sociology, v.9, n.1, p.70-89. 2015.

CALVET, Theresa.

Violência e/ou política. In: Friche Passos, Izabel (Org.). Poder, normalização e violência: incursões foucaultianas para a atualidade. Belo Horizonte: Autêntica. p.23-40. 2008.

CAMARGO, Luís Soares de.

Viver e morrer em São Paulo: a vida, as doenças e a morte na cidade do século XIX. Tese (Doutorado em História Social) - Pontifícia Universidade Católica de São Paulo, São Paulo. 2007.

CORDEIRO, Hésio.

A indústria de saúde no Brasil. Rio de Janeiro:

Graal. 1980.

DINIZ, Débora.

Estado laico, objeção de consciência e políticas de saúde. Cadernos de Saúde Pública, v.29, n.9, p.1704-1706. 2013.

ESCOREL, Sarah.

História das políticas de saúde no Brasil de 1964 a 1990: do golpe militar à reforma sanitária. In: Giovanella, Lígia et al. (Org.). Políticas e sistemas de saúde no Brasil. Rio de Janeiro: Editora Fiocruz. p.323-363. 2012

FOUCAULT, Michel. Vigiar e punir. Petrópolis: Vozes. 2012.

FOUCAULT, Michel.

Nascimento da biopolítica. São Paulo: Martins Fontes. 2008a.

FOUCAULT, Michel. Segurança, território e população. São Paulo: Martins Fontes. 2008b.

FOUCAULT, Michel.

História da sexualidade, 1: a vontade de saber. Rio de Janeiro: Graal. 2003.

FOUCAULT, Michel.

Sobre a história da sexualidade. In: Foucault, Michel. Microfísica do poder. Rio de Janeiro: Graal. p.243-276. 2000. 
GASPARI, Elio.

A ditadura encurralada. São Paulo: Companhia de Letras. 2004.

GLASER, Barney; STRAUSS, Anselm.

Time for dying. Chicago: Aldine. 1968.

GLASER, Barney; STRAUSS, Anselm.

Awareness of dying. Chicago: Aldine. 1965.

GOLDENBERG, Mirian.

A arte de pesquisar. Rio de Janeiro: Record. 1997.

HACKING, Ian.

How should we do the history of statistics? In: Burchell, Graham; Gordon, Colin; Miller, Peter (Org.). The Foucault effect: studies in governmentality. Chicago: The University of Chicago Press. p.181-196. 1991.

HOWARTH, Glennys.

Last rites: The work of the modern funeral director. New York: Routledge. 2016.

JORGE, Maria Helena Prado de Mello; LAURENTI, Ruy; GOTLIEB, Sabina Léa Davidson. O Sistema de Informações sobre Mortalidade SIM: concepção, implantação e avaliação. In: Ministério da Saúde; Opas; Fundação Oswaldo Cruz (Org.). A experiência brasileira em sistemas de informação em saúde: Produção e disseminação de informação sobre saúde no Brasil. Brasília: Editora do Ministério da Saúde. p.71-108. 2009.

LEBRÃO, Maria Lúcia.

Estudos de morbidade: usos e limites. Saúde e Sociedade, v.4, n.1-2, p.51-57. 1995.

LEMKE, Thomas.

Rethinking biopolitics: the new materialism and the political economy of life. In: Wilmer, Stephen Elliot; Žukauskaitè, Audronè (Org.). Resisting biopolitics: philosophical, political, and performative strategies. New York: Routledge. p.57-73. 2016.

\section{MINAS GERAIS.}

Corregedoria-geral de Justiça do Estado de Minas Gerais. Provimento n.260, de 30 de outubro de 2013. Disponível em: <http://www8.tjmg.jus.br/ institucional/at/pdf/cpr02602013.pdf $>$. Acesso em: 20 jan. 2018. 30 out. 2013.

MIRANDA, Francisco Cavalcanti Pontes de. Tratado de direito privado. São Paulo: Revista dos Tribunais. 1983.

NEAD, Lynda.

Myths of sexuality: representations of women in Victorian Britain. Oxford: Basil Blackwell. 1988.

NIOBEY, Flávia Maria Leal et al.

Qualidade do preenchimento de atestados de óbitos de menores de um ano na região metropolitana do Rio de Janeiro. Revista de Saúde Pública, v.24, n.4, p.311-318. 1990.

OMS.

Organização Mundial da Sáude. Classificação Estatística Internacional de Doenças e Problemas Relacionados à Saúde. 3 v. São Paulo: CBCD. 1995.

PARSONS, Brian.

Change and development of the British funeral industry in the 20th century with special reference to the period 1960-1994. Thesis (PhD) - University of Westminster, Westminster. 1997.

PAIM, Jairnilson Silva.

Reforma sanitária brasileira: contribuição para a compreensão e crítica. Salvador: Edufba; Rio de Janeiro: Editora Fiocruz. 2008.

PORTER, Theodore M.

Trust in numbers: the pursuit of objectivity in science and public life. Princeton: Princeton University Press. 1995.

PRIOR, Lindsay.

The social organisation of death: medical discourse and social practices in Belfast. London: Springer. 1989.

REIS, João José.

A morte é uma festa: ritos fúnebres e revolta popular no Brasil do século XIX. São Paulo: Companhia das Letras. 2012.

REVEL, Jacques.

A invenção da sociedade. Rio de Janeiro: Bertrand Brasil. 1990.

ROSE, Nicholas.

Powers of freedom: reframing political thought. Cambridge: Cambridge University Press. 1999.

SCHNEIDMAN, Edwin S.

Death: current perspectives. Palo Alto: Mayfield. 1976.

SILVA, Justino Adriano Farias da.

Tratado de direito funerário. 2 v. São Paulo: Método. 2000.

SILVEIRA, Maria Helena; LAURENTI, Ruy. Os eventos vitais: aspectos de seus registros e inter-relação da legislação vigente com as estatísticas de saúde. Revista de Saúde Pública, v.7, n.1, p.37-50. 1973.

SUDNOW, David.

Passing on: the social organization of dying. New Jersey: Prentice-Hall. 1967.

SZWARCWALD, Célia Landmann et al. Estimação da mortalidade infantil no Brasil: o que dizem as informações sobre óbitos e nascimentos do Ministério da Saúde? Cadernos de Saúde Pública, v.18, n.6, p.1725-1736. 2002. 
VASCONCELOS, Ana Morais.

A qualidade das estatísticas de óbitos no Brasil. Revista Brasileira de Estudos de População, v.15, n.1, p.115-124. 1998.

VIANA, Ana Luiza d'Ávila; MACHADO, Cristiani Vieira.

Descentralização e coordenação federativa: a experiência brasileira na saúde. Ciências e Saúde Coletiva, v.14, n.3, p.807-817. 2009.
WALTER, Tony.

The revival of death. London: Routledge. 2002.

WALTER, Tony.

On Bereavement: the culture of grief.

Buckingham: Open University Press. 1999.

WEBER, Max.

Ensaios de sociologia. Rio de Janeiro: Zahar. 1979.

ZIEGLER, Jean.

Os vivos e a morte. Rio de Janeiro: Zahar. 1977.

\section{$\rightarrow \rightarrow \rightarrow<<<$}

